\title{
Correction to: Chaperone-substrate interactions monitored via a robust TEM-1 $\beta$-lactamase fragment complementation assay
}

\author{
Ling Bai - Wei He - Tianpeng Li • Cuiting Yang • Yingping Zhuang • \\ Shu Quan
}

Published online: 4 February 2020

(C) Springer Nature B.V. 2020

Correction to: Biotechnol Lett (2017) 39:1191-1199

https://doi.org/10.1007/s10529-017-2347-9

In the original publication of the article, under the “Acknowledgement" section, the Grant No. 31611011097 should read as No. 31661143021.

Publisher's Note Springer Nature remains neutral with regard to jurisdictional claims in published maps and institutional affiliations.

The original article can be found online at https://doi.org/10.1007/s10529-017-2347-9.

L. Bai · W. He · T. Li · C. Yang · Y. Zhuang ·

S. Quan $(\bowtie)$

State Key Laboratory of Bioreactor Engineering,

Shanghai

Collaborative Innovation Center for Biomanufacturing

(SCICB), East China University of Science and

Technology,

130 Meilong Rd, Shanghai 200237, China

e-mail: shuquan@ecust.edu.cn 